\title{
Clinical Profile, Aetiology and Outcome of Afebrile Seizures in Children
}

\author{
Prakash Poudel, ${ }^{1}$ Prince Parakh, ${ }^{1}$ Kayur Mehta ${ }^{1}$ \\ 'Department of Paediatrics and Adolescent Medicine, BP Koirala Institute of Health Sciences, Dharan, Nepal.
}

\section{ABSTRACT}

Introduction: Clinical and outcome profiles of childhood seizures can be different in resource limited settings where neurologists face lots of challenges in diagnosis and management of seizure. This study was conducted to investigate the clinical profile, causes and outcome of afebrile seizures in children in resource limited settings.

Methods: This was a prospective hospital based study. Children with afebrile seizures were followed up with exclusion of febrile and acute provoked seizures. Clinical, investigation, treatment and outcome parameters were analyzed.

Results: Study included 308 (age one month to 20 years) children. Median age at first seizure was 39 (inter quartile range 12-96) months. History of status epilepticus was present in $26.0 \%$. Cause of seizure was known in $44.2 \%$. Seizure was generalized in $79.2 \%$, partial in $14.0 \%$ and unclassified in $6.8 \%$. Common causes of seizure were - birth asphyxia $(12.3 \%)$, neurocysticercosis $(8.8 \%)$, sequel of nervous system infection $(6.5 \%)$ and structural brain abnormalities (7.1\%). Neurological examination, electroencephalography and computed tomography (CT) were abnormal in $24.4 \%, 70.5 \%$ and $27.9 \%$ cases respectively. Seizure control was achieved in $79.3 \%$ and by monotherapy in $85.0 \%$ cases. Seizure control with single drug, seizure without recurrence and idiopathic seizure were associated with favourable outcome.

Conclusions: Prevention and control of birth asphyxia, neurocysticercosis and nervous system infections are needed to reduce the burden of afebrile seizures in this area. CT is a valuable diagnostic tool and response to monotherapy is good. Seizure control with single drug, seizure without recurrence and idiopathic seizure are favourable prognostic factors.

Keywords: afebrile seizure; children; clinical profile; outcome.

\section{INTRODUCTION}

On the basis of available figures it is agreed that between 1.5 to five percent of any population will have afebrile seizures at some time. ${ }^{1}$ Two unprovoked seizures greater than 24 hours apart suggest the presence of an epileptic disorder. ${ }^{2}$ Epilepsy is a common childhood morbidity and results from a variety of causes. ${ }^{3}$ One out of five children experience a seizure and almost one out of 200 children suffer from epilepsy. ${ }^{3}$ WHO estimates that, of the 50 million people with epilepsy in the world,
$80.0 \%$ live in developing countries. ${ }^{4}$ Though small hospital based studies regularly report several cases of childhood epilepsy, there is no published data regarding actual community prevalence of epilepsy in children in Nepal. ${ }^{5,6}$ Neurocysticercosis is a common cause of seizure in children in Nepal. ${ }^{6}$

Correspondence: Dr. Prakash Poudel,Department of Paediatrics and Adolescent Medicine, BP Koirala Institute of Health Sciences, Dharan, Nepal. Email: prakashpdl@hotmail.com, Phone: 9842025694. 
This study was conducted to investigate the occurrence, underlying causes, clinical profile, laboratory profile and outcome of afebrile seizures among children in resource constrained setting. Such studies provide information regarding burden, common causes, efficacy of treatment and prognosis of afebrile seizures among children in resource constrained settings where advanced facilities like Magnetic Resonance Imaging (MRI) and Electroencephalogram (EEG) are not easily accessible. Information provided by this and similar other studies are expected to help clinicians to adopt classification, management and prevention strategies as per existing scenario of resource constrained environment.

\section{METHODS}

This was a prospective hospital based study. All cases of afebrile seizures attending to paediatric neurology clinic of BP Koirala Institute of Health Sciences, Nepal, from July 1, 2009 to August 31, 2011 were included and followed up till January 31, 2012. Inclusion criteria were - age one month to 20 years, clinical diagnosis of seizure and attending to paediatric neurology clinic. The exclusion criteria were - neonates, febrile convulsion and acute symptomatic seizures.

Information about socio-demographic profile, history, possible risk factors and other important parameters were recorded. Diagnosis of seizure and epilepsy were made depending upon clinical description and history given by parents. Physical examination was done and recorded. Relevant investigations like computed tomography (CT) scan and EEG were advised when necessary. EEG was considered as abnormal when there was epileptiform discharge or slow wave abnormality. Seizure was classified using international classification of epileptic seizures proposed by International League Against Epilepsy (ILAE) in 1981.7 Diagnosis of comorbidities were made by history, physical examination and relevant investigations. Diagnosis of attention deficit hyperactivity disorder was made by criteria laid down by diagnostic and statistical manual of mental disorders, 4th edition, text revision. ${ }^{8}$ Patients were followed up in paediatric neurology clinic. During follow up, details of compliance, complications of anticonvulsant drugs, status of seizure control and modification in treatment were evaluated and recorded. Duration of follow up was calculated by adding retrospective follow up duration (time since first seizure to first medical attention) as given in history and prospective follow up duration (time since first attention till last visit before February 2012).

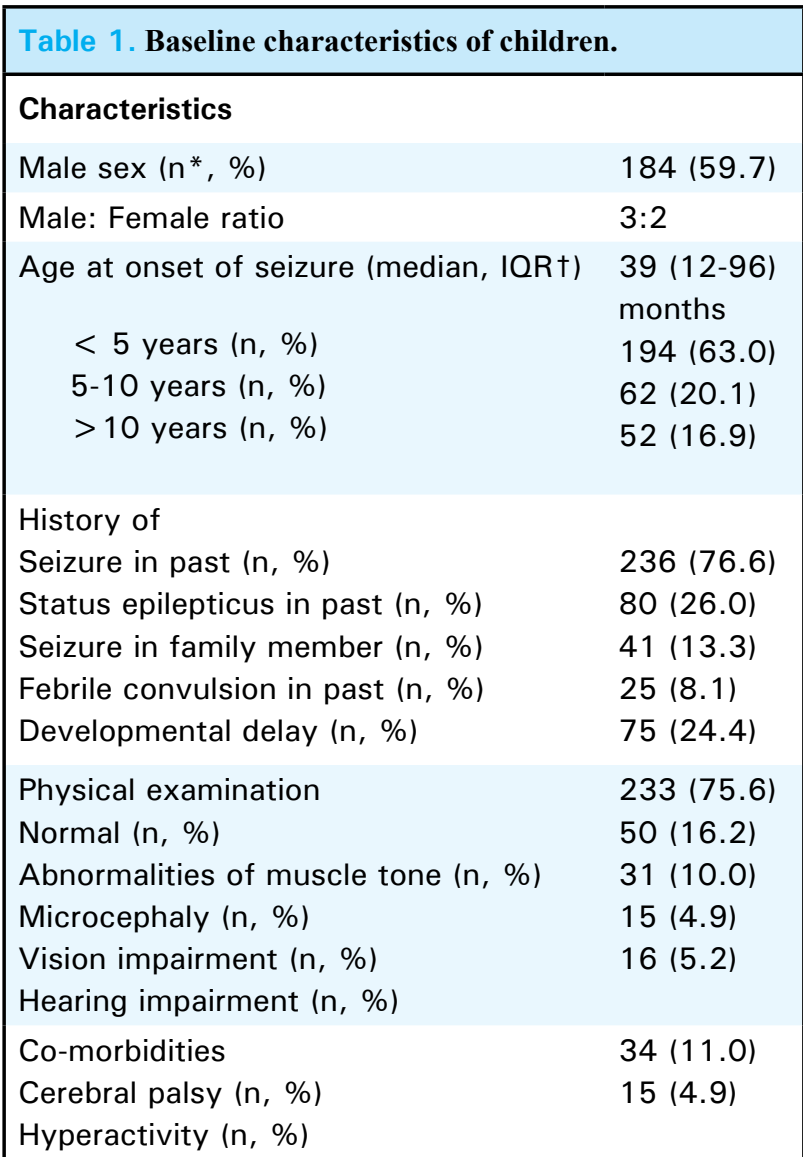

* $\mathrm{n}$ - Number of cases; $\uparrow \mathrm{IQR}$ - Inter quartile range

Data were entered and screened for error in MS Excel. The analysis was done using SPSS 11.5 software. Appropriate tests of significance were applied. Seizure was considered to be under good control when child remained seizure free for either at least two months or when seizure did not recur for two times the length of usual seizure free period between recurrences prior to treatment, whichever was longer. Cases with uncertain final seizure control status because of insufficient follow up duration or loss to follow up were excluded from outcome analysis. Possible factors that might affect final outcome were compared between the groups of children who achieved and who did not achieve good seizure control. The factors found to be significantly different between the groups on bivariate analysis by chi square or fisher exact tests were further analysed with logistic regression model. $P$ value of 0.05 was taken as cut off for statistical significance. Written consent was taken from parents. Ethical clearance was obtained from institutional ethical review board.

\section{RESULTS}

Baseline characteristics and co-morbidities: Study enrolled 308 children. Mental, developmental and neurological findings were normal in 233 (75.6\%) 
cases on physical examination. Table 1 shows baseline characteristics of children.

Classification of seizure types: Classification was done as per ILAE guideline $1981^{7}$ (Table 2).

\begin{tabular}{|lll|}
\hline \multicolumn{2}{|l|}{ Table 2. Classification of seizure types. } \\
\hline Seizure type & $\mathbf{N}^{*}$ & $\%$ \\
I. Generalized seizures & 244 & 79.2 \\
Tonic clonic & 180 & 58.4 \\
Tonic & 30 & 9.7 \\
Atonic & 19 & 6.2 \\
Absence & 6 & 1.9 \\
Atypical absence & 7 & 2.3 \\
Clonic & 1 & 0.3 \\
Myoclonic & 1 & 0.3 \\
II. Partial Seizures & 43 & 14 \\
Simple partial & 15 & 4.9 \\
Complex partial & 24 & 7.8 \\
Partial with secondary & 4 & 1.3 \\
generalization & 21 & 6.8 \\
III. unclassified &
\end{tabular}

\section{$N^{*}-$ Number of cases}

Causes of seizure: Causes of seizure were undetermined in most of the cases. Sequel of perinatal hypoxic brain injury was the most common identifiable cause of seizure. Table 3 shows causes of seizure.

Investigation findings: Out of $203(65.9 \%)$ cases that underwent CT scanning, abnormalities were detected in $86(42.4 \%)$ cases. In remaining cases CT was not done because of reasons like no indication, loss to follow up or inability to afford. Ring enhancing lesion $(29,14.3 \%)$, structural abnormality $(22,10.8 \%)$ and cerebral atrophy $(18,8.9 \%)$ were common abnormalities detected by CT scan among cases with available CT scan report. Out of $270(87.7 \%)$ cases that underwent EEG examination, $217(80.4 \%)$ cases had abnormal findings.
Table 3. Causes of seizures.

\begin{tabular}{|ll|}
\hline Causes of Seizure & $\mathbf{n}(\%)$ \\
\hline Unknown & $172(55.8)$ \\
Perinatal hypoxic brain injury & $38(12.3)$ \\
Neurocysticercosis & $27(8.8)$ \\
$\mathrm{CNS}^{\dagger}$ infections & $20(6.5)$ \\
$\mathrm{CNS}^{\dagger}$ structural abnormality & $22(7.1)$ \\
Stroke & $4(1.3)$ \\
Traumatic brain injury & $7(2.3)$ \\
Cerebral palsy of unknown cause & $7(2.3)$ \\
Others $^{c}$ & $11(3.6)$ \\
\hline
\end{tabular}

$\mathrm{N}^{*}$ - Number of cases; $\mathrm{CNS}^{\dagger}$ - Central nervous system;

${ }^{\ddagger}$ Calcified focus of undetermined origin 1 ,

Degenerative brain disease 1, Hydrocephalus 2,

Kernicterus 3, Tuberculoma 3, Tuberous sclerosis 1.

Follow up, treatment and outcome: edian duration of follow up was 24 (inter quartile range 8.25 to 48) months. There were $23(7.5 \%)$ cases that were lost to follow up. Therefore, outcome of seizure was known in 285 cases. Table 4 shows details of treatment and outcome.

\begin{tabular}{|c|c|c|}
\hline Details & $\mathbf{N}^{*}$ & $\%$ \\
\hline Good seizure control achieved & 226 & 79.3 \\
\hline Planned cessation of anticonvulsant & 67 & 23.5 \\
\hline Seizure controlled with monotherapy & 207 & 72.6 \\
\hline Requirement of polytherapy & 78 & 27.4 \\
\hline Side effect of anticonvulsants ${ }^{\dagger}$ & 37 & 13.0 \\
\hline Requirement of change of drug ${ }^{\ddagger}$ & 76 & 26.1 \\
\hline Requirement of increment of dose & 99 & 34.7 \\
\hline Total cases with known outcome & 285 & 100.0 \\
\hline
\end{tabular}

$\mathrm{N}^{*}$ - Number of cases; †Most common side effects were sedation and gingival hypertrophy due to phenytoin) in $8(2.6 \%)$ cases each; $¥$ Change of drug was done due to significant side effects or due to poor seizure control. 
Prakash et al. Clinical Profile, Aetiology and Outcome of Afebrile Seizures in Children

\begin{tabular}{|c|c|c|c|}
\hline \multirow[t]{2}{*}{ Characteristics } & \multirow{2}{*}{$\begin{array}{l}\text { Group A } \\
\mathbf{N}^{*}=227\end{array}$} & \multirow{2}{*}{$\begin{array}{r}\text { Group B } \\
n=58\end{array}$} & \multirow[t]{2}{*}{$\mathbf{P}$} \\
\hline & & & \\
\hline Onset below 5 years of age, $\mathrm{n}(\%)$ & $120(52.9 \%)$ & $46(79.3 \%)$ & $0.000^{b}$ \\
\hline Recurrent seizure, n (\%) & $162(71.4 \%)$ & $54(93.1 \%)$ & $0.001^{\mathrm{b}}$ \\
\hline Abnormal $\mathrm{CNS}^{\ddagger}$ physical examination, $\mathrm{n}(\%)$ & $34(15.0 \%)$ & $35(60.3 \%)$ & $0.000^{\mathrm{b}}$ \\
\hline Detectable underlying cause, $\mathrm{n}(\%)$ & $83(36.6 \%)$ & $46(79.3 \%)$ & $0.000^{\mathrm{b}}$ \\
\hline Requirement of polytherapy, n (\%) & $34(15.0 \%)$ & $44(75.9 \%)$ & $0.000^{b}$ \\
\hline Abnormal $\mathrm{CT}^{\S}$ scan, $\mathrm{n}(\%)$ & $55(35.5 \%)$ & $31(73.8 \%)$ & $0.000^{b}$ \\
\hline Male sex, n (\%) & $139(61.2 \%)$ & $31(53.4 \%)$ & 0.281 \\
\hline History of status epilepticus, n (\%) & $63(27.8 \%)$ & $12(20.7 \%)$ & 0.276 \\
\hline History of febrile convulsion, $\mathrm{n}(\%)$ & $20(8.8 \%)$ & $2(3.4 \%)$ & 0.172 \\
\hline Abnormal EEG ${ }^{\prime}, \mathrm{n}(\%)$ & $162(78.6 \%)$ & $47(90.4 \%)$ & 0.054 \\
\hline Family history of seizure, $\mathrm{n}(\%)$ & $30(13.2 \%)$ & $7(12.1 \%)$ & 0.871 \\
\hline
\end{tabular}

$\mathrm{N}^{*}$ - Number of cases; † Statistically significant; $¥$ CNS - Central nervous system;

$\S \mathrm{CT}$ - Computed tomography, || EEG - Electroencephalogram.

\begin{tabular}{|lll|}
\hline \multicolumn{2}{|l|}{ Table 6. Predictors of outcome on binary logistic regression. } \\
\hline Predictor of poor seizure control & $\mathbf{P}$ & $\begin{array}{l}\text { Odds ratio } \\
\text { (95\% confidence interval) }\end{array}$ \\
Recurrent seizure & $0.042^{*}$ & $3.6(1.05-12.33)$ \\
Presence of underlying cause & $0.002^{*}$ & $4.2(1.66-10.44)$ \\
Requirement of >1 anticonvulsant drug & $0.000^{*}$ & $10.6(4.90-22.99)$ \\
Seizure onset below 5 years age & 0.074 & $2.19(0.93-5.17)$ \\
Abnormal $\mathrm{CNS}^{\dagger}$ physical examination & 0.133 & $1.96(0.81-4.73)$ \\
Abnormal $\mathrm{CT}^{\ddagger}$ scan & 0.765 & $1.24(0.30-5.16)$ \\
\hline
\end{tabular}

* Statistically significant; † CNS - Central nervous system;

‡ CT - Computed tomography.

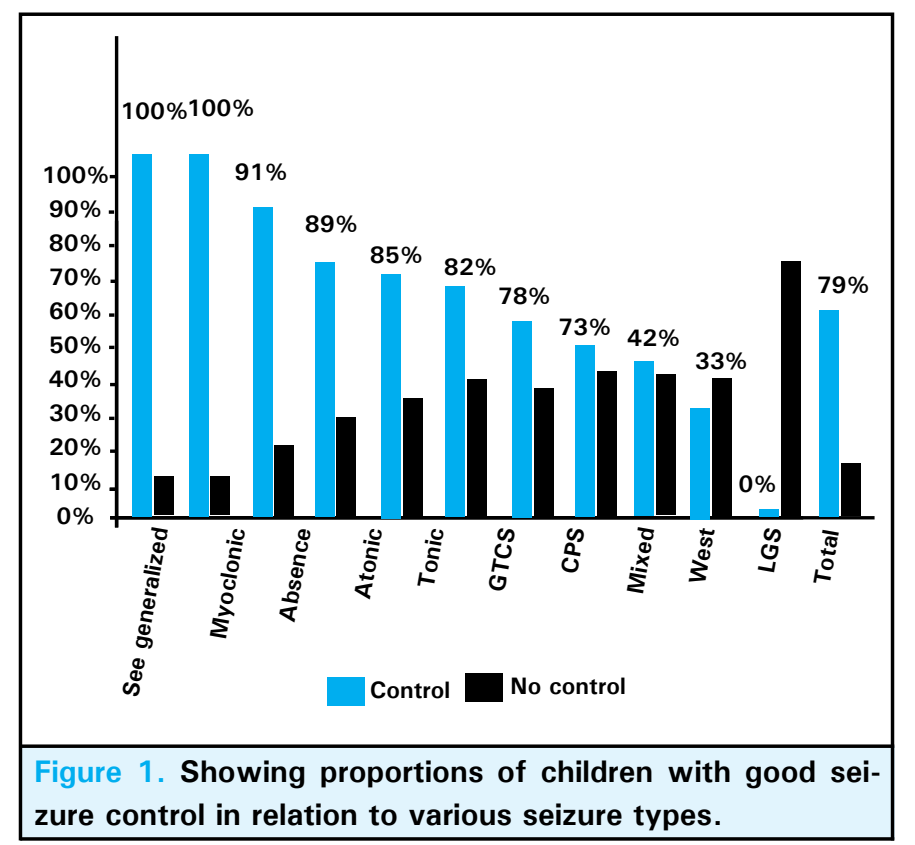


Good seizure control was achieved in $79.3 \%$ cases. Seizure control was achieved in higher proportion of cases with generalized seizure as compared to partial seizure. Children with mixed seizures and epilepsy syndromes had relatively poorer seizure control.

Prognostic factors: We compared possible predicting factors for seizure control between the groups of children who achieved and who did not achieve good seizure control. Table five shows comparison of those factors by bivariate analysis between the groups. The factors bearing statistical significance between the groups were further analysed with binary logistic regression method as shown in table six. The factors that were found to predict poor seizure control were - recurrent seizure, seizure with underlying cause, and need of more than one anticonvulsant drug for treatment.

\section{DISCUSSION}

Epidemiologic studies over the past few decades have greatly increased current knowledge of the incidence and prognosis of seizures. In most studies, age specific incidence rates are bimodally distributed with highest peak in first decade and within this decade in the first year of life. 1,9 Median age at onset of seizure in our study was 3.25 years, which is similar to the findings of other European studies. ${ }^{10,11}$ Majority (63.0\%) of children experienced first seizure before the age of five years in our study. In another study from Nepal, $40.0 \%$ of childhood seizure occurred between the ages of two to five years. ${ }^{5}$

Population based studies showed that the incidence of status epilepticus is $10-60$ per 100,000 person years, with the higher incidences occurring in poorer populations. ${ }^{12,13}$ An epidemiological study of children with status epilepticus in Japan found that the incidence of SE among Japanese children was higher than the reported incidence among Caucasian children. ${ }^{14}$ In our study, $26.0 \%$ cases experienced status epilepticus. Therefore, status epilepticus seems to be common in children with seizure in this region.

The precise risk of developing epilepsy after febrile seizure is unclear. ${ }^{15}$ Following a first febrile seizure, two to four percent children will experience at least one unprovoked seizure, and most of these children will subsequently develop epilepsy. ${ }^{16}$ Between $13.0 \%$ and $19.0 \%$ of children with afebrile seizures will have had one or more previous febrile seizure. ${ }^{9,17}$ In our study, $8.1 \%$ children had history of febrile convulsion. Epilepsy often runs in families. Family history of seizure was present in $13.3 \%$ children of our study. In a Spanish study, $23.5 \%$ children with epilepsy had family history of seizure. ${ }^{18}$
We found Cerebral palsy (CP) as the most common comorbidity associated with seizure. Prevalence of $\mathrm{CP}$ as high as $49.0 \%$ among epileptic children has been reported..$^{10}$ Many children with epilepsy have associated neurological deficit, behavioural and learning disorders. ${ }^{19}$ In our study, $\mathrm{CP}$, visual impairment and hearing impairment were present in $11.0 \%, 4.9 \%$ and $5.2 \%$ cases respectively, result being comparable to study by Waaler et al. ${ }^{9}$ Attention deficit and hyperactivity are found to be strongly associated with epilepsy. ${ }^{20}$ McDermott, et al. reported hyperactivity in $28.0 \%$ of children with epilepsy. ${ }^{20}$ We detected attention deficit hyperactivity in $4.9 \%$ cases. In a Norwegian study, attention deficit hyperactivity was present in $3.5 \%$ cases, result being almost similar to our study. ${ }^{9}$

We were able to classify seizure in $93.2 \%$ cases as per ILAE guideline $1981 .{ }^{7}$ Using the same classification, different studies from Europe reported proportions of unclassifiable seizures ranging from $1.5 \%$ to $4.0 \% .^{9,10}$ In our study, the most common seizure type was generalized. A Finnish study also reported generalized seizure to be more common than partial seizure. ${ }^{10}$ Proportions of generalized seizures as high as $78.0 \%, 88.0 \%$ and $65.0 \%$ have been reported from Nepal, China and India respectively. ${ }^{5,21,22}$ However, in studies in which particular care was taken with seizure classification and EEG was used, most children had partial seizures. ${ }^{9,18}$ These differences in results among the studies are, however, likely to be due to methodological problems. The categorization of seizure type is often difficult and partial seizures are often underreported. Many so-called generalized seizures in different studies, including our study, are probably secondarily generalized. The detection of a partial onset may depend on the skill of the investigator or the extent of investigation. In daily practice, neurologist frequently is confronted with the need to classify seizure on the basis of seizure observation or description only. ${ }^{23}$ This is true in resource limited settings where investigations are costly and not easily available.

In most studies, only two seizure types were common: tonic clonic and partial seizures. Other seizure types were uncommon. Generalized absence, for instance, is usually reported in less than two percent of patients. ${ }^{24}$ Our study also finds generalized tonic clonic seizure as the most common seizure type. We could identify the cause of seizure in $44.2 \%$ cases. In most of the studies from different parts of world, a putative aetiology for the epilepsy was found in $27.0 \%$ to $46.7 \%$ cases. . $^{9,10,25,26}$

Common causes of seizures in our study were birth asphyxia, neurocysticercosis, remote nervous system infections and structural abnormalities in brain. Birth injury has been found to be a major cause in many hospital based as well as field based studies. ${ }^{10,25,26}$ Unlike other 
western studies, neurocysticercosis was one of the most common causes of childhood seizure in our study. In Nepal and surrounding areas, neurocysticercosis is a major public health hazard. Various studies from Nepal and other developing countries across the world have reported neurocysticercosis as a cause of seizure in significant proportion of cases. ${ }^{6,22,26}$ These reports suggest that, where neurocysticercosis is endemic, seizure in the paediatric age group is highly suggestive and should be considered as a potential indicator of the disease.

Despite being better, MRI is not easily affordable and accessible in developing world, where CT scan is a cheaper alternative for investigating epilepsy. CT scan was abnormal in $42.4 \%$ of investigated cases in this study. CT scan abnormality as high as $70.0 \%$ has been reported in children with seizures from India. ${ }^{22} \mathrm{CT}$ scan was abnormal in $21.0 \%$ cases among investigated children with seizure in study by Gibbs et al. ${ }^{27}$ Our study revealed that ring enhancing cerebral lesion, diffuse or focal brain atrophy and structural abnormality in brain were the common neuroimaging findings detected by CT scan. These findings are similar to the findings of an Indian study. ${ }^{22}$ Atrophy was the most common abnormality found in nine percent of investigated children in study by Gibbs et al, the result being similar to our study. ${ }^{27}$

The EEG itself neither proves nor excludes a diagnosis of seizure, but is nevertheless essential in the diagnostic workup and proper classification of epileptic seizures and syndromes. EEG was abnormal in $80.4 \%$ of investigated cases in our study which is much higher than reported by other studies (16.0\%-48.0\%) done in childhood seizure. ${ }^{27,28}$ Higher proportion of EEG abnormality in our study might be because of highly selected cases undergoing EEG evaluation and probably because of misinterpretation. The EEG may show paroxysmal activity or background changes in up to $32.0 \%$ of normal children that could be misinterpreted as abnormal. ${ }^{29}$

In our study, good seizure control was achieved in $79.3 \%$ cases out of 285 cases with known outcome. Seizure was resistant to initial therapy in remaining $20.7 \%$ cases. This result is similar to the result of a study by Waaler et al. They found $13.1 \%$ cases to be resistant to therapy. ${ }^{9}$ In our study, generalized and partial seizures were the easy to control seizure types whereas mixed seizures and epilepsy syndromes were difficult to control seizure types. This finding of our study is similar to the findings of a study done in Finnish children. ${ }^{10}$ Published literature shows that up to $70.0 \%$ of childhood epilepsies will respond to the first or second drug. ${ }^{30}$ We achieved good seizure control in majority $(72.6 \%)$ of cases with monotherapy. Significant side effects were reported by $13.0 \%$ cases in our study. Sedation and gingival hypertrophy were two most common side effects in $2.6 \%$ cases each. Similar to this result, Eriksson et al. have reported side effects in $14.0 \%$ children treated for epilepsy. ${ }^{10}$ Waaler et al. found side effects in $26.4 \%$ children with sedation as the most common side effect in $9.6 \%$ cases. $^{9}$

We analyzed various factors that might be associated with outcome of seizure. Seizure control with monotherapy, first seizure without recurrence and absence of underlying cause were the factors that predicted good seizure control.

In conclusion, as per this hospital based study in resource limited settings of a developing country, generalized seizures are more common than partial seizures when clinical description is used for classification. Cause of seizure can be identified in many cases by CT scan and other simple tests. Birth asphyxia, neurocysticercosis and nervous system infections are common causes and prevention of these diseases is an important measure to reduce the burden of seizures in this area. Good seizure control can be achieved by monotherapy in majority of cases. Seizure control with single drug, seizure without recurrence and idiopathic seizure are the factors associated with favourable outcome.

\section{CONCLUSIONS}

Prevention and control of birth asphyxia, neurocysticercosis and nervous system infections are needed to reduce the burden of afebrile seizures in this area. CT is a valuable diagnostic tool and response to monotherapy is good. Seizure control with single drug, seizure without recurrence and idiopathic seizure are favourable prognostic factors.

\section{ACKNOWLEDGEMENTS}

We would like to acknowledge to all resident doctors who helped to collect data and also to all children and parents who participated in study. This research work was partially presented in $14^{\text {th }}$ ASEAN Paediatric Congress, Singapore in April, 2011 and in Korean Epilepsy Congress, Incheon, Korea in June, 2012. 


\section{REFERENCES}

1. Sander JW, Shorvon SD. Epidemiology of the epilepsies. J Neurol Neurosurg Psychiatry. 1996 November;61(5):433-43.

2. Johnston MV. Seizures in Childhood. In: Behman RE, Kleigman RM, Jenson HB, editors. Nelson Textbook of Pediatrics. 17thed. Philadelphia: Saunders; 2004. p. 1993-2005.

3. Kalra V. Management of Childhood Epilepsy. Indian J Pediatr. 2000 Jan;67(1 Suppl):S12-21.

4. WHO. The world health report: mental health-new understanding, new hope. Geneva: World Health Organization; 2001.

5. Shakya KN, Shrestha R, Baral MR. Epilepsy in children: an epidemiological study at Kathmandu Medical College Teaching Hospital Kathmandu. Kathmandu Univ Med J. 2003;1(1):14-9.

6. Shrestha BM. Childhood Neurocysticercosis: Clinico-Radiological Profile and Outcome. J Nepal Paediatr Society. 2008;28(1):14-6.

7. Commission on Classification and Terminology of the International League Against Epilepsy. Proposal for revised clinical and electroencephalographic classification of epileptic seizures. Epilepsia. 1981;22(4):489-501.

8. American Psychiatric Association. Diagnostic and Statistical Manual of Mental Disorders. 4th ed. Washington, DC: American Psychiatric Association; 2000.

9. Waaler PE, Blom BH, Skeidsvoll H, Mykletun A. Prevalence, Classification, and Severity of Epilepsy in Children in Western Norway. Epilepsia. 2000;41(7):802-10.

10. Eriksson KJ, Koivikko MJ. Prevalence, Classification, and Severity of Epilepsy and Epileptic Syndromes in Children. Epilepsia. 1997;38(12):1275-82.

11. Durá-Travé T, Yoldi-Petri ME, Gallinas-Victoriano F. Epilepsy in children in Navarre, Spain: epileptic seizure types and epileptic syndromes. J Child Neurol. 2007;22(7):823-8.

12. Coeytaux A, Jallon P, Galobardes B, Morabia A. Incidence of status epilepticus in French-speaking Switzerland: (EPISTAR). Neurology. 2000;55(5):693-7.

13. DeLorenzo RJ, Hauser WA, Towne AR, Boggs JG, Pellock JM, Penberthy L, et al. A prospective, population-based epidemiologic study of status epilepticus in Richmond, Virginia. Neurology. 1996;46(4):1029-35.

14. Nishiyama I, Ohtsuka $Y$, Tsuda $T$, Kobayashi K, Inoue H, Narahara K, et al. An epidemiological study of children with status epilepticus in Okayama, Japan: incidence, etiologies, and outcomes. Epilepsy Res. 2011;96(1-2):89-95.

15. Waruiru C, Appleton R. Febrile seizures: an update. Arch Dis Child. 2004;89(8):751-6.
16. Annegers JF, Hauser WA, Shirts SB, Kurland LT. Factors prognostic of unprovoked seizures after febrile convulsions. N Engl J Med. 1987;316(9):493-8.

17. Camfield P, Camfield C, Gordon K, Dooley J. What types of epilepsy are preceded by febrile seizures? A population-based study of children. Dev Med Child Neurol. 1994;36(10):887-92.

18. Dura-Trave T, Yoldi-Petri ME, Gallinas-Victoriano F. A descriptive study of childhood epilepsy. Rev Neurol. 2007;44(12):720-4

19. Vinayan KP. Epilepsy, Antiepileptic Drugs and Educational Problems. Indian Pediatrics. 2006;43(9):786-94.

20. McDermott S, Mani S, Krishnaswami S. A population based analysis of specific behavior problems associated with childhood seizures. J Epilepsy. 1995;8(2):110-8.

21. Li SC, Schoenberg BS, Wang CC, Cheng XM, Zhou SS, Bolis CL. Epidemiology of epilepsy in urban regions of the People's Republic of China. Epilepsia. 1985;26(5):391-4.

22. Mishra S, Das BK, Srivastava AK. Neuroimaging study in children with seizures. J Nepal Paediatr Society. 2007;27(1):13-6

23. Parra J, Augustijn PB, Greets $\mathrm{Y}$, van Emde Boas W. Classification of Epileptic Seizures: A Comparison of Two Systems. Epilepsia. 2001;42(4):476-82.

24. Sander JW. The epidemiology and prognosis of typical absence seizures. In: Duncan JS, Panayiotopoulos CP, editors. The typical absences and related epileptic syndromes. Edinburgh: Churchill Livingstone; 1994. p. 135-41.

25. Granieri E, Rosati G, Tola R, Pavoni M, Paolino E, Pinna L, et al. A descriptive study of epilepsy in the district of Copparo, Italy 1964-1978. Epilepsia. 1983;24(4):502-14.

26. Placencia M, Shorvon SD, Paredes V, Bimos C, Sander JW, Cascante SM, et al. Epileptic seizures in an Andean region of Ecuador: incidence and prevalence and regional variation. Brain. 1992;115(3):771-82.

27. Gibbs J, Appleton RE, Carty H, Beirne M, Acomb BA. Focal electroencephalographic abnormalities and computerised tomography findings in children with seizures. J Neurol Neurosurg Psychiatry. 1993 Apr;56(4):369-71.

28. Bachman DS, Hodges FJ, Freeman JM. Computerized axial tomography in chronic seizure disorders of childhood. Pediatrics. 1976 Dec;58(6):828-32.

29. Eeg-Olofsson O. The development of the electroencephalogram in normal children and adolescents from the age of 1 through 21 years. Acta Paediatr Scand. 1971;208:(Suppl 208):1-46.

30. Kwan P, Brodie MJ. Effectiveness of first antiepileptic drug. Epilepsia. 2001 Oct;42(10):1255-60. 